\title{
Limiares térmicos para a germinação de conídios de Cercospora sojina em dois regimes luminosos
}

\author{
Juliane Nicolodi Camera ${ }^{1,2}$; Carolina Cardoso Deuner ${ }^{1}$; Erlei Melo Reis ${ }^{1}$; Camila Ranzi ${ }^{1}$
}

${ }^{1}$ Universidade de Passo Fundo, Campus I, Bairro São José - BR 285 - KM 171, Caixa Postal 611, Passo Fundo, RS, Brasil. CEP 99052$900 .{ }^{2}$ Parte da dissertação de mestrado. Autor para correspondência:

Autor para correspondência: Carolina Cardoso Deuner (carolinadeuner@upf.br)

Data de chegada: 25/09/2012. Aceito para publicação em: 15/03/2013.

\section{RESUMO}

Camera, J.N.; Deuner, C.C.; Reis, E.M.; Ranzi, C. Limiares térmicos para a germinação de conídios de Cercospora sojina em dois regimes luminosos. Summa Phytopathologica, v.39, n.1, p.58-61, 2013.

O objetivo desse trabalho foi avaliar a germinação de conídios de Cercospora sojina em diferentes temperaturas com luz contínua e no escuro, visando a determinar os limiares térmicos inferior e superior e a temperatura ótima. Os conídios foram depositados na superfície das placas de petri contendo substrato ágar-água. Em seguida foram incubadas em DBO com luz contínua e no escuro nas temperaturas $\left(0 ; 5 ; 10 ; 15 ; 20 ; 25 ; 30 ; 35\right.$ e $\left.40{ }^{\circ} \mathrm{C}\right)$ e retiradas nos tempos de exposição (3, 6, 9 e 12 horas). Para os conídios de C. sojina submetidos à luz contínua no tempo de exposição de 3 horas, verificou-se que a maior germinação ocorreu na temperatura de $23,8{ }^{\circ} \mathrm{C}$, para 6 horas foi de $24,3{ }^{\circ} \mathrm{C}$, para 9 horas foi de $22,9{ }^{\circ} \mathrm{C}$ e para 12 horas foi de $22,4^{\circ} \mathrm{C}$. Quando as placas foram incubadas no escuro, verificou-se que a maior germinação dos conídios para o tempo de exposição de 3 horas foi na temperatura de $23,8{ }^{\circ} \mathrm{C}$, para 6 horas foi de $23,4{ }^{\circ} \mathrm{C}$, para 9 horas foi de $22,9{ }^{\circ} \mathrm{C}$ e para 12 horas $22,7^{\circ} \mathrm{C}$. A temperatura ótima para a germinação de conídios na luz contínua foi de $22,4{ }^{\circ} \mathrm{C}$ e no escuro de $23{ }^{\circ} \mathrm{C}$, sendo o limiar térmico inferior de $0{ }^{\circ} \mathrm{C}$ e o superior de $40{ }^{\circ} \mathrm{C}$.

Palavras-chave adicionais: Mancha "olho-de-rã", fotoperíodo, esporos, Glycine max.

\section{ABSTRACT}

Camera, J.N.; Deuner, C.C.; Reis, E.M.; Ranzi, C. Temperature threshold for Cercospora sojina conidium germination under two light regimens. Summa Phytopathologica, v.39, n.1, p.58-61, 2013.

The aim of this study was to evaluate the germination of Cercospora sojina conidia at different temperatures under continuous light and in the dark in order to determine the lower and the upper temperature threshold, as well as the optimum temperature. Conidia were deposited on the surface of Petri plates containing agar-water substrate. They were then incubated in BOD under continuous light and in the dark at different temperatures $(0 ; 5 ; 10 ; 15 ; 20 ; 25 ; 30 ; 35$ and $40{ }^{\circ} \mathrm{C}$ ) and withdrawn at different exposure times (3, 6, 9 and 12 hours). For C. sojina conidia subjected to continuous light for the exposure time of 3 hours, the best germination occurred at a temperature of $23.8{ }^{\circ} \mathrm{C}$, for 6 hours at $24.3{ }^{\circ} \mathrm{C}$, for 9 hours at $22.9{ }^{\circ} \mathrm{C}$ and for 12 hours at $22.4{ }^{\circ} \mathrm{C}$. When the plates were incubated in the dark, conidium germination was greater when exposure time was 3 hours at a temperature of $23.8{ }^{\circ} \mathrm{C} 6$ hours at $23.4{ }^{\circ} \mathrm{C}, 9$ hours at 22.9 ${ }^{\circ} \mathrm{C}$ and 12 hours at $22.7{ }^{\circ} \mathrm{C}$. The optimum temperature for conidium germination under continuous light was $22.4{ }^{\circ} \mathrm{C}$ and in the dark it was $23{ }^{\circ} \mathrm{C}$, while the lower temperature threshold was $0{ }^{\circ} \mathrm{C}$ and the upper threshold was $40{ }^{\circ} \mathrm{C}$.

Additional keywords: Frogeye leaf spot, photoperiod, spores, Glycine max.

A soja [Glycine max (L.) Merr.] é uma planta herbácea pertencente à família das Fabaceas. Esta planta é originária do sudoeste asiático e há relatos de seu cultivo a mais de 6 mil anos na China. Atualmente, é uma das mais importantes leguminosas cultivadas em todo o mundo (3).

No Brasil, a área semeada com a cultura na safra 2010/2011 foi de 24,08 milhões de hectares, um crescimento de $2,6 \%$ em relação a safra 2009/10, quando foram cultivados 23,47 milhões de hectares (7).

Dentre as doenças que ocorrem na cultura pode-se destacar a mancha foliar "olho-de-rã", cujo agente causal é Cercospora sojina
Hara (2). Esse fungo foi descrito pela primeira vez em 1915 no Japão, foi relatado nos Estados Unidos em 1924 (11) e no Brasil sua ocorrência foi verificada somente em 1970, ocorrendo no estado do Paraná. A partir deste primeiro foco no Brasil, o fungo espalhou-se por todo o país, através de sementes infectadas, sendo que em 1973, Reis \& Kimati (17) detectaram a doença no Rio Grande do Sul.

De acordo com trabalho de Yorinori \& Klingelfuss (20), a mancha foliar "olho-de-rã" foi a primeira grande epidemia na cultura de soja, sendo responsável pelo início do programa de melhoramento genético visando resistência às doenças no Brasil. Na safra 1970/71, o fungo $C$. 
sojina foi introduzido através de um lote de sementes da cultivar Bragg, originada dos Estados Unidos, sendo o mesmo semeado no Paraná. A partir deste primeiro foco, o fungo disseminou-se por todo o estado causando severas perdas nos quatro anos seguintes. $\mathrm{Na}$ Argentina, safra 1997/1998, Ploper e colaboradores (15), relataram que na região de Tucumán algumas plantas isoladas apresentavam severidade foliar da doença inferior a $1 \%$, nos anos seguintes esta severidade chegou a $10 \%$, sendo que na última safra causou uma epidemia severa na Argentina, manifestando-se com severidade de 30-60\% (6).

$\mathrm{O}$ aparecimento e desenvolvimento de uma doença são resultantes da interação entre uma planta suscetível, um agente patogênico e ambiente favorável. Desses três componentes, apenas o ambiente apresenta alterações frequentes e importantes no decorrer do ciclo de uma cultura, pois a suscetibilidade do hospedeiro e a virulência/ agressividade da população patogênica pouco se altera nesse curto período de tempo. É o ambiente que regula o desenvolvimento das epidemias, podendo, inclusive, impedir sua ocorrência mesmo que hospedeiros suscetíveis e patógenos virulentos estejam presentes (3).

A temperatura age como catalisador dos processos biológicos, razão pela qual, tanto as plantas como os patógenos requerem uma temperatura mínima para crescer e desenvolver normalmente suas atividades. Em certas faixas de temperatura, normalmente mais altas, os patógenos tornam-se ativos e, quando a umidade torna-se favorável, podem infectar as plantas e, consequentemente, causar doença (16). Segundo Phillips (14), os conídios do fungo C. sojina germinam em uma hora na superfície dos folíolos de soja, quando a temperatura encontra-se na faixa de $25-30{ }^{\circ} \mathrm{C}$.

Este trabalho teve como objetivo avaliar a germinação de conídios de C. sojina em diferentes temperaturas com luz contínua e no escuro, visando determinar os limiares térmicos inferior e superior e a temperatura ótima.

O presente trabalho foi desenvolvido no Laboratório de Fitopatologia da Faculdade de Agronomia e Medicina Veterinária da Universidade de Passo Fundo, em câmaras do tipo DBO (Demanda Biológica de Oxigênio), sendo o delineamento experimental inteiramente casualizado com quatro repetições.

As temperaturas testadas foram $0 ; 5 ; 10 ; 15 ; 20 ; 25 ; 30 ; 35$ e $40{ }^{\circ} \mathrm{C}$ com tempos de exposição de 3, 6, 9 e 12 horas com luz contínua e no escuro.

O inóculo de $C$. sojina raça 25 , utilizado nesse trabalho foi fornecido pela Embrapa Soja, sendo preservado na micoteca do Laboratório de Fitopatologia da Universidade de Passo Fundo. Primeiramente realizou-se o isolamento monospórico, no qual fragmentos de colônias de C. sojina preservado em tubos contendo BDA (Batata-Dextrose-Ágar) (18) foram transferidos para placas de petri contendo meio de cultura extrato de tomate (10). As placas permaneceram em câmara de crescimento, a $25{ }^{\circ} \mathrm{C}$ e com fotoperíodo de 12 horas durante 30 dias, até obter-se esporulação abundante. Posterior à esporulação do fungo, adicionou-se na placa de petri, 10 $\mathrm{mL}$ de água destilada e esterilizada com a finalidade de obter-se uma suspensão de conídios. Dessa suspensão foi pipetado $1 \mathrm{~mL}$, e depositado em placas de petri contendo substrato ágar-água a $1 \%$, e incubadas a $25{ }^{\circ} \mathrm{C}$ com fotoperíodo de 12 horas por um período de 12 horas. Decorrido este tempo, observou-se a germinação dos conídios e com o auxílio de uma espátula esterilizada foram cortados 10 cubos de substrato ágar-água, sendo que em cada um deles havia somente um conídio germinado. Cada cubo foi transferido para uma placa de petri contendo meio de cultura extrato de tomate (10), sendo incubadas a 25 ${ }^{\circ} \mathrm{C}$ com fotoperíodo de 12 horas durante 30 dias, até obter-se esporulação abundante.
A partir das culturas puras obtidas pelo isolamento monospórico, preparou-se uma suspensão de conídios, da qual $600 \mu \mathrm{L}$ da suspensão que foram depositados em placas de petri esterilizadas contendo o substrato ágar-água $1 \%$ para cada uma das temperaturas testadas. As placas foram mantidas em DBO durante 3, 6, 9 e 12 horas, com luz contínua e no escuro, sendo que para essa última as placas foram envolvidas com papel alumínio. Decorrido o tempo desejado, as placas foram retiradas da $\mathrm{DBO}$ e foram adicionados $2 \mathrm{~mL}$ de uma solução de acetona sem corante com a finalidade de paralisar o crescimento do fungo. Este procedimento foi realizado para cada tempo, regime luminoso e tempo de exposição.

Determinou-se a germinação de 100 conídios sob microscópio óptico com magnitude de 40 vezes, através da mensuração do tubo germinativo. Considerou-se germinado quando o seu comprimento foi maior que largura do conídio (21).

A temperatura ótima para a geminação dos conídios foi calculada através da média dos resultados obtidos pela fórmula da regressão de cada um dos tempos testados. O limiar térmico inferior e superior foram as temperaturas, nas quais não se observou a germinação dos conídios de C. sojina. Os dados obtidos foram submetidos à análise de variância e de regressão.

Para a germinação dos conídios de $C$. sojina quando submetidos à luz contínua no tempo de exposição de 3 horas (Figura 1), verificou-se que a maior percentagem de germinação ocorreu na temperatura de $23,8{ }^{\circ} \mathrm{C}$, para 6 horas foi de $24,3{ }^{\circ} \mathrm{C}$, para 9 horas foi de $22,9^{\circ} \mathrm{C}$ e para 12 horas foi de $22,4^{\circ} \mathrm{C}$. A média da temperatura para a germinação dos conídios com luz contínua nos quatro tempos de exposição foi de $23,3{ }^{\circ} \mathrm{C}$ e a temperatura ótima foi de $22,4{ }^{\circ} \mathrm{C}$.

Quando as placas foram incubadas no escuro (Figura 2), verificou-se que maior percentagem de germinação dos conídios, no tempo de exposição de 3 horas foi na temperatura de $23,8{ }^{\circ} \mathrm{C}$, para 6 horas foi de $23,4{ }^{\circ} \mathrm{C}$, para 9 horas foi de $22,9{ }^{\circ} \mathrm{C}$ e para 12 horas de $22,7{ }^{\circ} \mathrm{C}$. A média da temperatura para a germinação dos conídios no escuro nos quatro tempos de exposição foi de $23,2{ }^{\circ} \mathrm{C}$ e a temperatura ótima foi de $23{ }^{\circ} \mathrm{C}$.

Observou-se que, os conídios de C. sojina quando submetidos às temperaturas de $0{ }^{\circ} \mathrm{C}$ e $40{ }^{\circ} \mathrm{C}$ não apresentaram germinação com luz contínua e no escuro, portanto, concluiu-se que o limiar térmico inferior foi de $0{ }^{\circ} \mathrm{C}$ e o limiar térmico superior foi de $40{ }^{\circ} \mathrm{C}$.

De acordo com estudos realizados por Yorinori (19), a germinação e a esporulação de $C$. sojina em soja foi restringida por temperaturas abaixo de $20{ }^{\circ} \mathrm{C}$. Gómez (9) relata que a temperatura ótima para a germinação de conídios de $C$. soijna foi de $25{ }^{\circ} \mathrm{C}$, sendo que esses dados corroboram com os obtidos nesse trabalho. Segundo Phillips (14), conídios de $C$. sojina germinaram com temperaturas compreendidas na faixa entre $25-30{ }^{\circ} \mathrm{C}$, e no tempo de uma hora, quando na superfície dos folíolos de soja.

C. sojina é um fungo imperfeito que se reproduz por esporos assexuais denominados de conídios. Cada espécie de fungo requer uma temperatura ótima para o seu crescimento vegetativo e reprodutivo (1). De modo geral, a temperatura tem maior influência nas atividades do patógeno do que o teor de água no substrato e da umidade relativa do ar. Todas as fases do ciclo das relações patógeno-hospedeiro são influenciadas pela temperatura. No processo de reprodução, a temperatura pode alterar tanto a velocidade de produção de esporos quanto o número de propágulos formados (3). De acordo com Mian e colaboradores (12), a faixa de temperatura para a ocorrência da mancha foliar "olho-de-rã" varia de $25-30^{\circ} \mathrm{C}$. Segundo Cruz (8), a temperatura de $25^{\circ} \mathrm{C}$ favorece o crescimento miceliano para alguns isolados de $C$. sojina amostrados nos EUA, sendo que para isolados adaptados para 


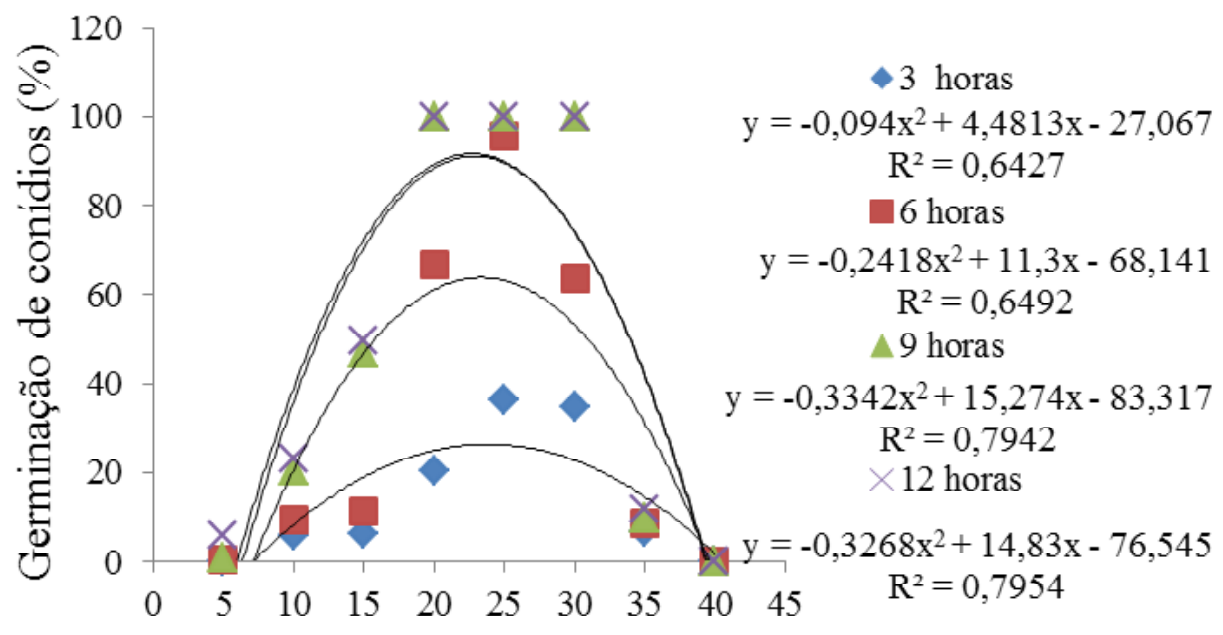

Temperatura $\left({ }^{\circ} \mathrm{C}\right)$

Figura 1. Efeito da temperatura e do tempo de exposição na germinação de conídios de Cercospora sojina sob luz contínua. Passo Fundo, RS. 2011.

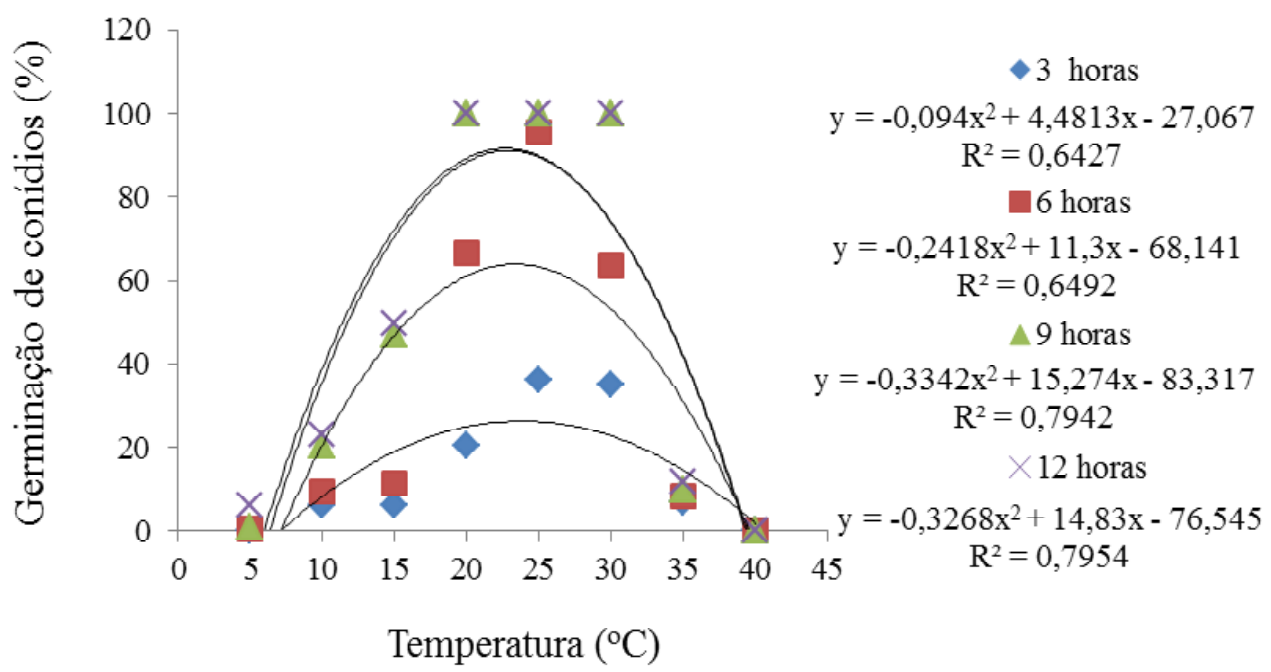

Figura 2. Efeito da temperatura e do tempo de exposição na germinação de conídios de Cercospora sojina no escuro. Passo Fundo, RS. 2011.

a região norte, as temperatura ótimas podem diferir. Esse mesmo autor dbteve crescimento miœdiano de $C$. sojina nas temperaturas entre 17 e $21{ }^{\circ} \mathrm{C}$, sendo a temperatura ótima de $25^{\circ} \mathrm{C}$.

Segundo Alfenas (1), é importante determinar as exigências térmicas do microrganismo quando de seu cultivo in vitro, com o objetivo de definir o menor tempo necessário para a produção do inóculo requerido em trabalhos de pesquisa.

Em trabalhos realizados por Carlini (5) com Phakopsora pachyrhizi Sydow, cujo patossistema ocorre juntamente na cultura com $C$. sojina, os resultados obtidos foram semelhantes aos encontrados neste trabalho, pois o limiar térmico inferior foi de $6,0^{\circ} \mathrm{C}$, na qual ocorreu menor comprimento do tubo germinativo. Abaixo dessa temperatura não ocorreu à germinação dos uredosporos, sendo que a temperatura ótima obtida foi de $21{ }^{\circ} \mathrm{C}$, onde o tubo germinativo teve maior comprimento. $\mathrm{O}$ limite térmico superior foi $35^{\circ} \mathrm{C}$, sendo que acima dessa não ocorreu a germinação dos uredosporos.

Dados semelhantes aos obtidos neste experimento com $C$. sojina foram encontrados por Melo e Reis (13) para o patossistema Corynespora cassiicola (Berk. \& Curtis) Weirem e soja, sendo a temperatura ótima para a germinação de conídios de C. cassiicola é de $23^{\circ} \mathrm{C}$. Os conídeos do patógeno germinam em uma ampla faixa de temperatura, sendo que seu limiar térmico inferior foi de $7{ }^{\circ} \mathrm{C}$ e o superior de $39{ }^{\circ} \mathrm{C}$.

Conforme os resultados obtidos no presente trabalho, podemos concluir que: A temperatura ótima para a germinação de conídios de $C$. sojina é de $23^{\circ} \mathrm{C}$. Os conídeos de $C$. sojina germinam em uma ampla faixa de temperatura, sendo que seu limiar térmico inferior é de $0^{\circ} \mathrm{C}$ e o limiar térmico superior é de $40^{\circ} \mathrm{C}$. A luz não influencia na germinação dos conídios de $C$. sojina.

\section{REFERÊNCIAS BIBLIOGRÁFICAS}

1. Alfenas, A.C.; Mafia, R.G. Métodos em fitopatologia, Viçosa, MG: Ed. UFV 2007. 382p.

2. Akem, C.N.; Dashiell, K.E. Effect of planting date on severity of frogeye leaf spot and grain yield of soybean. Crop Protection, Florida, v.13, p.607-610. 1994.

3. Amorin, L.; Bedendo, I.P. Ambiente e doença. In: Bergamin Fi- 
lho, A. (Ed.). Manual de fitopatologia. 3 ed. São Paulo: Agronômica Ceres, 1995. p.331-341.

4. Borém, A. Escape gênico: os riscos do escape gênico da soja no Brasil. Biotecnologia Ciência \& Desenvolvimento, Brasília, v.10, p.101-107, 1999.

5. Carlini, R.C. Germinação de uredosporos e período latente de Phakopsora pachyrhizi determinado por tempo cronológico unidades de calor. 2009. 63f. Dissertação (Mestrado em Agronomia) - Faculdade de Agronomia e Medicina Veterinária, Universidade de Passo Fundo, Passo Fundo.

6. Carmona, M.A.; Scandiani, M.M. Epidemias de la mancha ojo de rana en la región pampeana: caracterización y manejo. In: Actas Rosário: Congreso de La Asociación Argentina de Productores en Siembra Directa (Aapresid), 17, 2009. p. 225-228.

7. Companhia Nacional de Abastecimento. Estimativas de safras da produtividade brasileira da safra 2010/2011, Brasília, 2011. Acesso em: 05 set. 2012.

8. Cruz, C.D. Impact of foliar diseases on soybean in Ohio: frogeye leaf spot and septoria Brown spot. 2008. $99 \mathrm{f}$. Dissertação (Mestrado da Ciência), Escola de Graduados da Universidade Estadual de Ohio, Estados Unidos.

9. Gómez, D.E Cercospora sojina: produção de esporos, densidade de inóculo e reação de cultivares de soja. 2011. 94f. Dissertação (Mestrado em Agronomia) - Faculdade de Agronomia e Medicina Veterinária, Universidade de Passo Fundo, Passo Fundo.

10. Hine, R.B.; Aragaki, M. Influence of soil temperature on a crown rot disease of parsley caused by Phytophthora parasitic. Phytopathology, St. Paul, v.53, p.1113-1114, 1963.

11. Lehman, S.G. Frog-eye leaf spot on soybean caused by Cercospora diazu Miura. Journal Agricultural Research, Pakistan v.36, p.811-833. 1928
12. Mian, M.A.; Missaoui, A.M.; Walker, D.R.; Phillips, D.V. Boerma, H.R. Frogeye leaf spot of soybean: a review and proposed race designations for isolates of Cercospora sojina Hara. Crop Science, Madison, v.48 p.14-24, 2008.

13. Melo, M.M.; Reis, E.M. Patogenicidade de Corynespora cassiicola em soja, limiares térmicos e temperatura ótima para a germinação de conídios em meio de cultura. Summa Phytopathologica, Botucatu, v.36, n.3, p.254-256, 2010.

14. Phillips, O.V. Frogeye leaf spot. In: hartman, G.L.; sinclair, J.B.; Rupe, J.C. Compendium of Soybean Diseases. Saint Paul: APS Press, 1999. p. 20-21.

15. Ploper, L.D.; Gonzalez, V.; Galvez, R.; Devani, M.; Ledesma, F. La mancha ojo de rana. Outra enfermedad limitante del cultivo de la soja. Avance Agroindustrial, Tucumán, v.21, p.9-12. 2000.

16. Reis, E.M.; Bresolin, A.C.R. Sistemas de previsão de doenças de plantas. In: Reis, E.M. Previsão de doenças de plantas. Passo Fundo: UPF, 2004. p.155-287.

17. Reis, E.M.; Kimati, H. Nota sobre ocorrência de Cercospora sojina Hara, causando a mancha foliar "olho-de-rã" em soja, no Rio Grande do Sul. Revista O solo, Uruguaiana, v.2, p.55. 1973.

18. Tuite, J. Plant Pathological Methods: fungi and bacterial. Minneapolis: Burgess Publishing Company. 1969. 239p.

19. Yorinori, J.T. Identificação de raças de Cercospora sojina (mancha "olho-de-rã") e distribuição geográfica. Resultados da pesquisa de soja 1988/89. CNPSO/EMBRAPA. Londrina, v.43 p.405, 1989.

20. Yorinori, J.T.; Klingelfuss, L.H. Novas raças de Cercospora sojina em soja. Fitopatologia Brasileira, Lavras, v.24, p.509-12. 2000 .

21. Zadocks, J.C.; Schein, R.D. Epidemiology and plant disease management. New York: Oxford University Press, 1979. 427p. 